\title{
ARTICLE OPEN The role of metal vacancies during high-temperature oxidation of alloys
}

\author{
Richard P. Oleksak (D) ${ }^{1,2}$, Monica Kapoor (iD), Daniel. E. Perea $\mathbb{D}^{3}$, Gordon R. Holcomb (D) and Ömer N. Doğan (D)
}

An improved understanding of high-temperature alloy oxidation is key to the design of structural materials for next-generation energy conversion technologies. An often overlooked, yet fundamental aspect of this oxidation process concerns the fate of the metal vacancies created when metal atoms are ionized and enter the growing oxide layer. In this work, we provide direct experimental evidence showing that these metal vacancies can be inseparably linked to the oxidation process beginning at the very early stages. The coalescence of metal vacancies at the oxide/alloy interface results initially in the formation of low-density metal and eventually in $\mathrm{nm}$-sized voids. The simultaneous and subsequent oxidation of these regions fills the vacated space and promotes adhesion between the growing oxide and the alloy substrate. These structural transformations represent an important deviation from conventional metal oxidation theory, and this improved understanding will aid in the development of new structural alloys with enhanced oxidation resistance.

npj Materials Degradation (2018)2:25 ; doi:10.1038/s41529-018-0046-1

\section{INTRODUCTION}

The oxidation behavior of structural alloys at high temperatures is central to the function of power plants, aircrafts, and many other high-temperature applications. ${ }^{1}$ During exposure to these harsh environments, an oxide layer is formed on the alloy surface, which protects the metal below from further degradation. Often this occurs by the diffusion of metal cations from the oxide/alloy interface to the oxide surface, where an equal number of metal vacancies are created at the oxide/alloy interface. The behavior of these vacancies is not considered in conventional metal oxidation theory, ${ }^{2}$ which effectively assumes that they are constantly annihilated at the oxide/alloy interface. ${ }^{3}$ This is equivalent to the alloy shrinking in volume as oxidation proceeds, resulting in a moving interface, which is structurally unchanged throughout the oxidation process. If the vacancies are not all so annihilated, then they may be transferred into the underlying alloy in a process known as vacancy injection. ${ }^{3}$

Although initially a controversial topic, ${ }^{4}$ it is now well established that vacancy injection occurs during hightemperature oxidation in many alloy systems. ${ }^{5-7}$ There have been several hypotheses as to the fate of these vacancies and the proposed mechanisms can largely be separated into two categories. The first is vacancy annihilation; if vacancies are not annihilated at the oxide/alloy interface, then they may instead be annihilated at suitable sinks in the alloy such as dislocations, ${ }^{8}$ grain boundaries, ${ }^{6}$ or free surfaces not covered with an oxide. ${ }^{5}$ The second is vacancy condensation; during this process, vacancies coalesce and precipitate as voids at the oxide/alloy interface, ${ }^{7,9,10}$ at grain boundaries, ${ }^{11}$ or elsewhere in the alloy. For the case of voids formed at the oxide/alloy interface the process is analogous to void formation by the Kirkendall effect, ${ }^{12}$ where different countercurrent diffusion rates result in a net flux of vacancies across an interface. ${ }^{13}$ This phenomenon has been used, for example, to produce hollow metal oxide nanoparticles ${ }^{14-16}$ and while these studies do confirm that void formation can occur by vacancy injection, it is difficult to relate results to the oxidation behavior of a structural alloy component in service. This is because considerable differences exist for the two systems, most notably the boundary conditions for diffusion. In general, attempts at quantifying the extent of vacancy condensation in systems that resemble an oxidizing structural alloy have shown that it accounts for only a small fraction of the vacancies theoretically generated during oxidation. ${ }^{6,17}$ The fate of most of the vacancies, and thus their role in the oxidation process, remains largely unknown.

The extent of vacancy condensation has important implications related to the growth stresses associated with oxidation. For example, volume expansion that accompanies internal oxidation of an alloy matrix or of secondary phases such as metal carbides ${ }^{18}$ is generally assumed to create stresses in the alloy. However, no such stresses need arise if this oxidation serves to fill the space created by vacancy condensation. On the contrary, this could prevent growth of large voids near the oxide/alloy interface which might otherwise lead to oxide delamination. Thus, the volume change associated with oxidation relative to that made available by vacancy condensation is an important parameter in considering the stability of a growing oxide layer.

Difficulties in investigating the behavior of injected metal vacancies is partly related to the short time- and length-scales at which vacancy formation and migration occur. This is especially true of the early stages of oxidation, which can be difficult to capture experimentally, and requires instrumentation capable of resolving and visualizing structural and compositional changes approaching the atomic scale. ${ }^{19}$ Nevertheless, it is during these early stages that oxide growth is fastest and the ensuing vacancy generation at a maximum. In this contribution, we present insights into this behavior by assessing the surface of a structural alloy

\footnotetext{
${ }^{1}$ National Energy Technology Laboratory, 1450 Queen Ave SW, Albany, OR 97321, USA; ${ }^{2}$ AECOM, PO Box 618 , South Park, PA 15129 , USA and ${ }^{3}$ Environmental Molecular Sciences Laboratory, Pacific Northwest National Laboratory, 902 Battelle Blvd, Richland, WA 99352, USA

Correspondence: Richard P. Oleksak (Richard.Oleksak@netl.doe.gov)
}

Received: 26 March 2018 Revised: 23 July 2018 Accepted: 24 July 2018

Published online: 05 September 2018 
during the early stages of oxidation. Alloy 617 was selected for the study, as representative of a class of solution-strengthened $\mathrm{Ni}$ superalloys, which are used for many applications requiring exceptional mechanical strength and oxidation resistance at high temperatures. ${ }^{20}$ From an oxidation perspective, Alloy 617 is generally considered to be a Ni-Cr-Al alloy, where long-term exposure results in the formation of a continuous external layer of $\mathrm{Cr}_{2} \mathrm{O}_{3}$ and internal precipitates of $\mathrm{Al}_{2} \mathrm{O}_{3} \cdot{ }^{21}$ The oxidized alloy was evaluated in detail following a short exposure to high-temperature $\mathrm{CO}_{2}$ and results reveal the important role of the metal vacancies formed during this process.

\section{RESULTS}

Following exposure (details provided in the methods section below), the material was analyzed by cross-sectional scanning transmission electron microscopy (STEM) using a high-angle annular dark-field (HAADF) detector. To distinguish the general features present at the oxide/alloy interface, a high-magnification STEM image showing a region representative of most of the oxidized surface is presented in Fig. 1. From bottom to top, the image shows the alloy substrate, the oxide formed during exposure, and a layer of Pt deposited on the sample surface to prevent ion beam damage during preparation of the specimen. In this STEM image, regions of light contrast represent higher average atomic mass and/or higher density relative to darker regions (see methods section below). Thus, the alloy substrate appears lighter in contrast while the oxide appears darker. The oxide layer is $\approx 10-20 \mathrm{~nm}$ thick (taken from several regions across the surface), indicating that the sample represents an early stage in the oxidation pathway of the alloy. The oxide is generally welladhered to the alloy substrate, however, close inspection reveals regions of varying contrast at the oxide/alloy interface indicating a possible difference in the composition and/or density in these regions. Most notably, regions of intermediate contrast are observed immediately below the oxide to a depth of $\approx 10 \mathrm{~nm}$ into the alloy substrate. The origin of this contrast variation is revisited below.

Although the majority of the oxidized surface appeared similar to that shown Fig. 1, relatively large regions of dark contrast were also observed sporadically across the oxide/alloy interface ${ }^{22}$ such as that shown in Fig. 2 a. This region extends $\approx 200 \mathrm{~nm}$ across the oxide/alloy interface and $\approx 20 \mathrm{~nm}$ into the alloy substrate. Energy dispersive X-ray spectroscopy (EDS) mapping (Fig. 2b-e) shows that no X-ray signal is detected for the areas of darkest contrast in this region (indicated with solid arrows in Fig. 2). This suggests these areas are voids that have formed during oxidation. This is consistent with previous observations, where $\mathrm{nm}$-sized voids were observed periodically across the oxide/alloy interface. ${ }^{22}$ Additional regions of interfacial voiding are shown in the supplementary information (Fig. S1). Figure 2 also reveals that the oxide layer is $\mathrm{Cr}$-rich and contains no $\mathrm{Ni}$.

The existence of voids at the oxide/alloy interface at such an early stage is compelling evidence for vacancy injection, and would be difficult to rationalize by alternative explanations

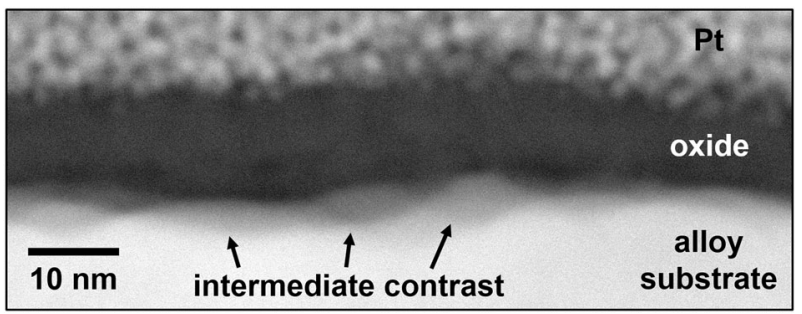

Fig. 1 STEM cross-sectional image of a region characteristic of most of the oxidized surface involving growth stresses, particle dissociation, etc. ${ }^{23}$ Further, $\mathrm{Cr}$ diffuses faster than $\mathrm{Ni}$ in $\mathrm{Ni}-\mathrm{Cr}$ alloys ${ }^{24}$ and any vacancy flux arising from countercurrent diffusion in the alloy (i.e., Kirkendall effect) would be directed downward and not expected to accumulate at the oxide/alloy interface. Thus, vacancies generated during the selective oxidation of $\mathrm{Cr}$ were injected into the alloy and coalesced to form voids near the oxide/alloy interface. A small amount of material is also observed throughout the dark contrast region adjacent to the voids (indicated with dashed arrows in Fig. 2), and EDS mapping reveals it is predominantly Al-oxide. This Al-oxide network is dispersed throughout an otherwise voided zone, and together these features comprise the region of dark contrast observed in Fig. 2a. It should be noted that O observed in the alloy substrate (Fig. 2d) is most likely an artifact of imperfect peak deconvolution of the $\mathrm{X}$-ray spectra leading to partial misassignment of $\mathrm{Cr}(\mathrm{Cr} \mathrm{La}=573 \mathrm{eV})$ as O $(\mathrm{O} \mathrm{Ka}=525 \mathrm{eV})$. This also has the effect of diluting the $\mathrm{O}$ signal arising from the porous Al-oxide network, as the maps are presented as non-normalized raw counts (see methods section below).

To gain insight into the intermediate contrast regions present at the oxide/alloy interface, a higher magnification EDS map was acquired at another region along the sample surface as shown in Fig. 3. The regions of intermediate contrast present at the oxide/ alloy interface are seen to contain Al-oxide and, in some areas, $\mathrm{Cr}$ oxide. Surprisingly, the same regions are also seen to contain $\mathrm{Ni}$. We showed previously that $\mathrm{Ni}$ in the sample was present nearly exclusively in the metallic state. ${ }^{22}$ Thus, it appears that clusters of Al-oxide (and to some extent, $\mathrm{Cr}$-oxide), which were too small to be resolved by the STEM analysis, have formed that are dispersed in what remains of the surface of the Ni alloy substrate, to a depth on the order of $10 \mathrm{~nm}$ below the oxide layer. An additional feature of interest is also observed: a portion of the oxide layer is seen to protrude downward into the alloy substrate near the middle of Fig. 3a, as illustrated by similarities in contrast (Fig. 3a) and $\mathrm{Cr}$ content (Fig. $3 \mathrm{c}$ ) relative to the rest of the oxide layer. Although this could be related to a microstructural feature or groove present at the sample surface prior to oxidation, analysis of an unexposed sample ${ }^{22}$ revealed a very smooth surface, suggesting that the oxide has in fact grown inward in this region. Further, a region of darker contrast (defined by the white dashed circle in Fig. 3) is observed in the STEM image near the right side of this inward-growing oxide. The same region corresponds to low X-ray counts for all elements, suggesting it is lower in density. Finally, the presence of a Cr-depleted region in the top $\approx 15 \mathrm{~nm}$ of the alloy confirms that oxide growth has proceeded in part by the outward diffusion of $\mathrm{Cr}$ ions, consistent with the creation of metal vacancies in the alloy.

Although the above STEM/EDS results provide some evidence into the behavior of the metal vacancies generated during oxidation, the projection effect inherent in the two-dimensional nature of the analysis makes precise interpretation difficult. Further, artifacts created during ion beam thinning of the specimen (which could, for example, preferentially attack certain regions of the sample resulting in density variations) cannot be ruled out. Therefore, to provide further insight into the structure and composition of the oxide/alloy interface at the atomic scale, atom probe tomography (APT) was used. An APT reconstruction of an ionized specimen which captures the oxide/alloy interface is presented in Fig. 4. Maps are shown for all ions, $\mathrm{Ni}$ ions, $\mathrm{Cr}$ and $\mathrm{Cr}-$ containing oxide $\left(\mathrm{Cr}_{x} \mathrm{O}_{y}\right)$ ions, $\mathrm{O}$ ions, and $\mathrm{Al}$ and $\mathrm{Al}$-containing oxide $\left(\mathrm{Al}_{\mathrm{x}} \mathrm{O}_{\mathrm{y}}\right)$ ions in a selected 3 -nm thick sliced region extracted from the APT reconstruction. Because $\mathrm{Ni}$ in the alloy has participated only minimally in the oxidation process, ${ }^{22}$ the distribution of $\mathrm{Ni}$ ions can be used to visualize what remains of the alloy substrate. Maps showing the distribution of $\mathrm{O}, \mathrm{Cr}+$ $\mathrm{Cr}_{x} \mathrm{O}_{y}$, and $\mathrm{Al}+\mathrm{Al}_{\mathrm{x}} \mathrm{O}_{\mathrm{y}}$ in the APT reconstruction reveal several features that are consistent with the STEM results. The surface oxide layer is $\mathrm{Cr}$-rich, a region of $\mathrm{Cr}$-depletion is observed $\approx 15 \mathrm{~nm}$ 

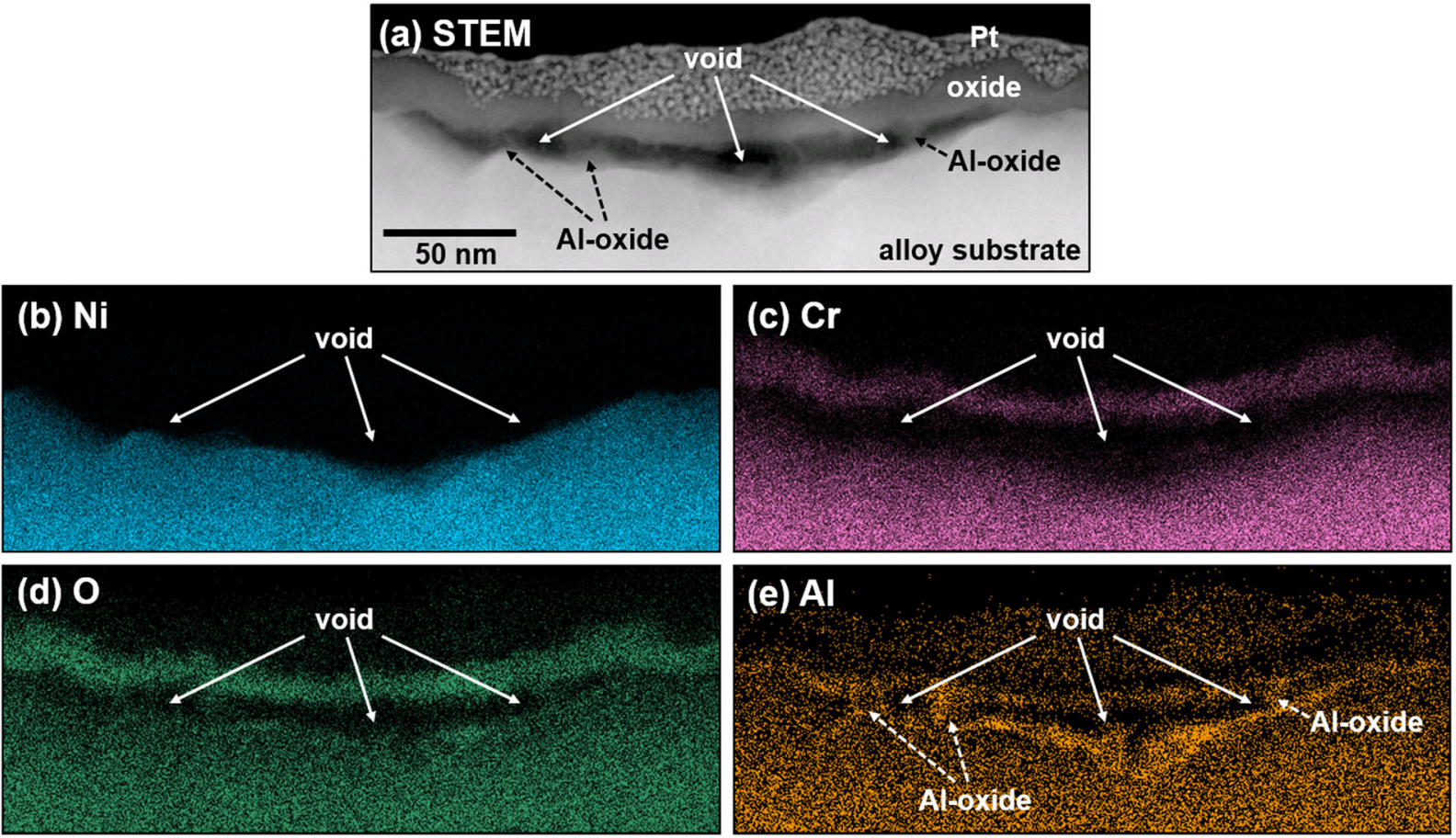

Fig. 2 STEM cross-sectional analysis of the oxidized surface. a STEM image of an area containing a dark contrast region at the oxide/alloy interface. $\mathbf{b}-\mathbf{e}$ EDS maps of the area shown in a

into the alloy substrate, and Al-oxide exists as a continuous layer at the oxide/alloy interface. Further, an inward-growing oxide that contains both $\mathrm{Al}$ and $\mathrm{Cr}$ extends to the bottom of the $\mathrm{Cr}$-depleted region, similar to that observed by STEM analysis (Fig. 3). Analogous to the low-density region seen near the inwardgrowing oxide in the STEM image (Fig. 3a), a region containing fewer ions is clearly observed below the oxide/alloy interface in the APT maps showing all ions and $\mathrm{Ni}$ ions. Thus, a region of low density is observed in the alloy to a depth of $\approx 5-10 \mathrm{~nm}$ below the oxide layer.

It should be noted that trajectory aberrations arising from differences in evaporation field can lead to spatial overlap and therefore to artificial density variations in the APT reconstruction that are not characteristic of actual density variations in the material. ${ }^{25}$ This is especially true for the interfaces of materials with significantly different evaporation fields, such as those between metals and oxides as in our study. Therefore, it is not possible to quantify density variations using APT. However, many studies have shown that it is possible to identify the existence of voids and other low-density regions, for example, by using isodensity (atoms $/ \mathrm{nm}^{3}$ ) surfaces. ${ }^{26-29}$ We used a similar analysis to confirm the presence of low-density regions in this study, as discussed further below.

To gain insight into the low-density regions and to visualize their relationship with the surrounding oxidation processes in three dimensions, iso-composition surfaces (sometimes referred to as iso-concentration surfaces) were generated in a 10-nm thick slice of the same region of APT reconstruction as shown in Fig. 4. Figure $5 \mathrm{a}, \mathrm{b}$ shows surfaces corresponding to $>55$ at $\% \mathrm{Ni}$ ions and $>21$ at $\%(\mathrm{Al}+\mathrm{O})$ ions, which delineate the low-density and inward-growing oxide regions observed in Fig. 4. In addition to the single low-density region observable in the ion maps (Fig. 4), the $\mathrm{Ni}$ iso-composition surface reveals additional regions of low density not observable in the ions maps, which are located in the top $\approx 10 \mathrm{~nm}$ of the alloy in the vicinity of the inward-growing oxide. An iso-density surface ${ }^{26}$ of $\mathrm{Ni}$ for this same volume (shown in Fig. S2 of the supplementary information) confirms that the regions of low at $\% \mathrm{Ni}$ are indeed also lower in atomic density (i.e., fewer atoms per volume). The co-location of the $\mathrm{Ni}$ and $(\mathrm{Al}+\mathrm{O})$ iso-composition surfaces in Fig. $5 \mathrm{a}$, $\mathrm{b}$ reveals that regions of high $\mathrm{Ni}$ content correspond precisely with regions of Al-oxide. Thus, regions consisting of residual alloy and Al-oxide clusters are observed in the vicinity of low-density regions in the substrate. The location of the iso-composition surfaces (in the alloy substrate immediately below the oxide layer) and the co-existence of $\mathrm{Ni}$ metal and Al-oxide in the same region, is in good agreement with STEM analysis (Fig. 3a, b, e). This suggests that these features are responsible for the intermediate contrast regions observed by STEM imaging, which were present across most of the oxide/alloy interface (Fig. 1).

To further investigate the relationship between the low-density and adjacent oxidized regions, a one-dimensional atom count profile was obtained through the inward-growing oxide region as shown in Fig. $5 \mathrm{c}$. Ions present in the volume defined by the 3-nm diameter cylinder shown in Fig. $5 c$ were used to generate the line profile (a 1-nm bin width was used). Thus, the profile presents the number of detected atoms of each element as a function of position. As described above, this analysis does not provide a quantitative assessment of the density, however qualitative variations are revealed. For clarity, $\mathrm{Ni}$ ions are shown, whereas the other relatively high-concentration alloying elements that participated minimally in the oxidation process (Co and Mo) are omitted. These elements followed the Ni trace at values close to what is expected for the bulk alloy (shown in Fig. S3 of the supplementary information) and thus the Ni trace is representative of what remains of the alloy substrate following oxidation. As with the iso-composition surfaces (Fig. 5a, b), the Ni-rich region of the line profile is correlated with the oxidized region, which contains both $\mathrm{Al}$ and $\mathrm{Cr}$. On both sides of the oxidized region, the total number of atoms decreases considerably. This is in part owing to the lack of oxide in these regions. However, a decrease in the number of $\mathrm{Ni}$ atoms is also clearly observed from $\approx 200$ in the oxidized region to $\approx 80$ and $\approx 160$ on the left and right side of the oxidized region, respectively. There is no compensating increase in the number of other atoms in these regions. This confirms the existence of regions of decreased density within the partially 

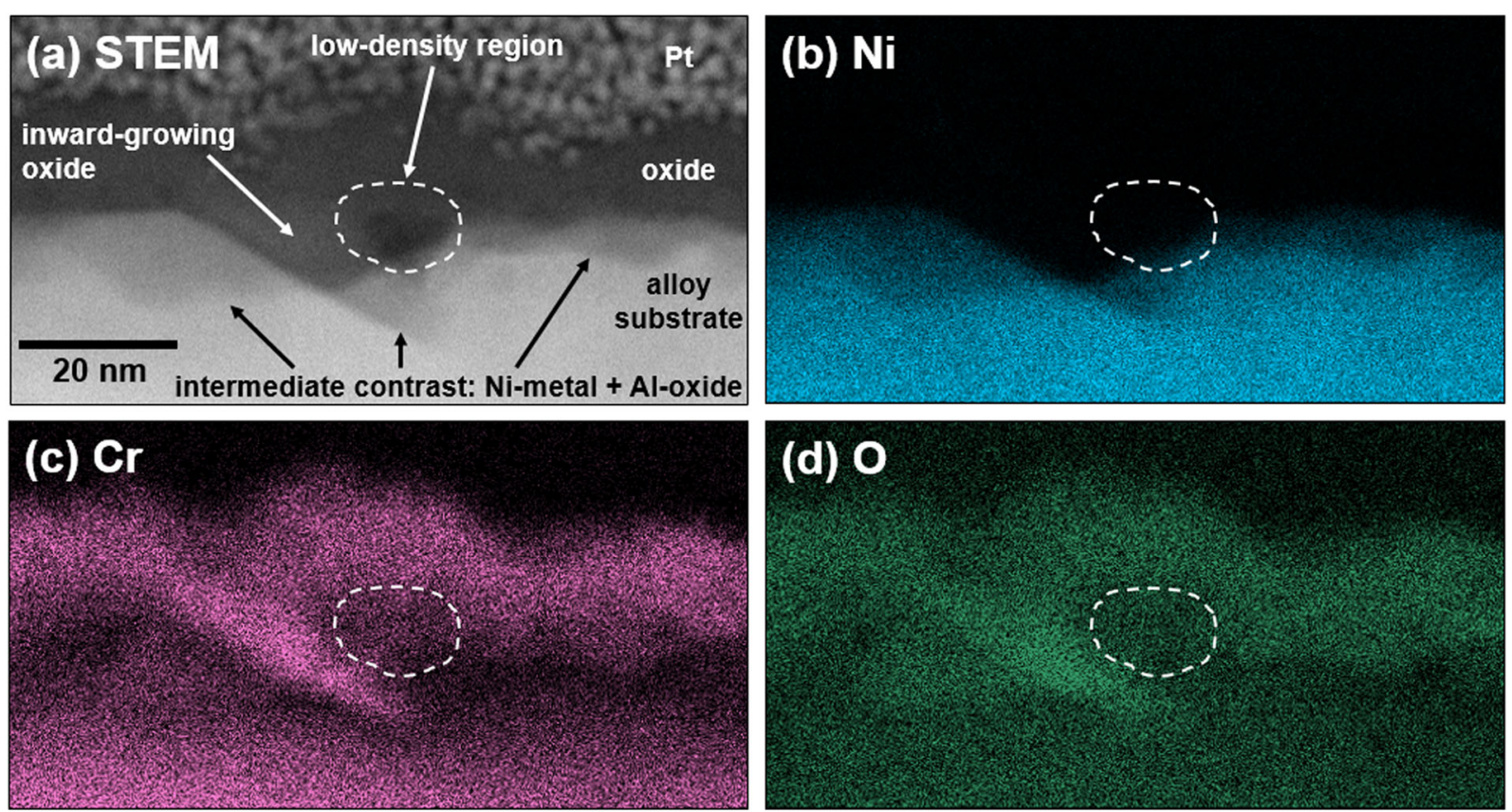

\section{(d) 0}

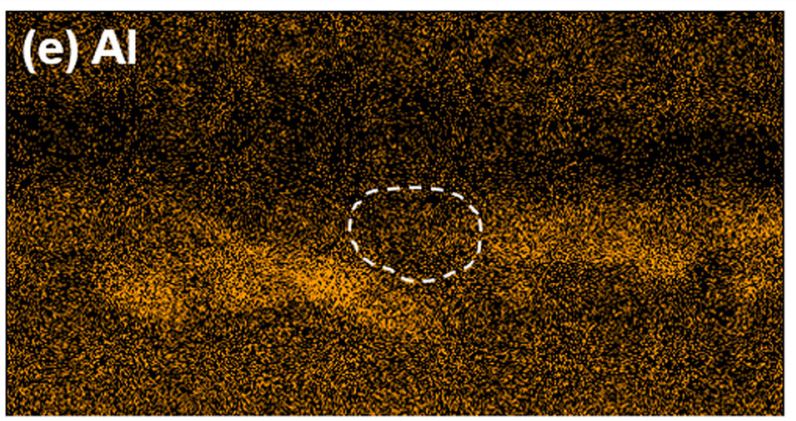

Fig. 3 STEM cross-sectional analysis of the oxidized surface. a STEM image of a region containing areas of various contrast at the oxide/alloy interface. $\mathbf{b}-\mathbf{e}$ EDS maps of the area shown in a

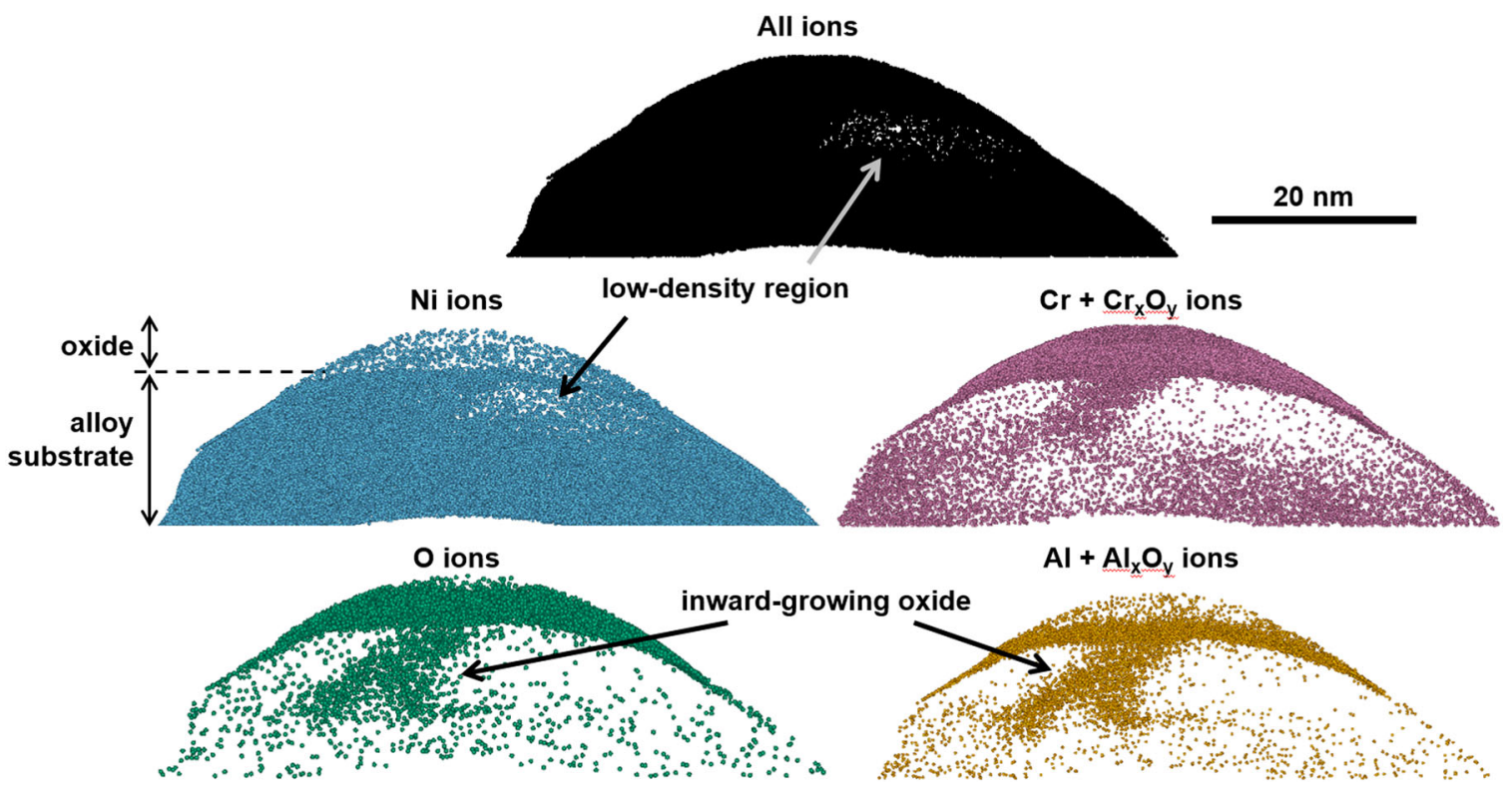

Fig. 4 APT ion maps of the oxide/alloy interface. Maps corresponding to a 3-nm thick slice of the APT reconstruction show all ions, Ni ions, $\mathrm{Cr}$ and $\mathrm{Cr}$-containing oxide $\left(\mathrm{Cr}_{\mathrm{x}} \mathrm{O}_{\mathrm{y}}\right)$ ions, $\mathrm{O}$ ions, and $\mathrm{Al}$ and $\mathrm{Al}$-containing oxide $\left(\mathrm{Al}_{\mathrm{x}} \mathrm{O}_{\mathrm{y}}\right)$ ions 
(c)

(a)

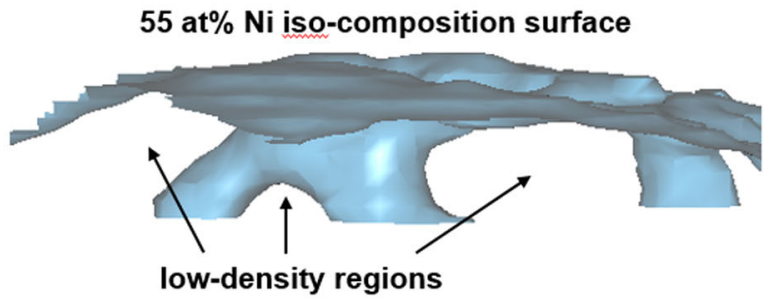

(b)

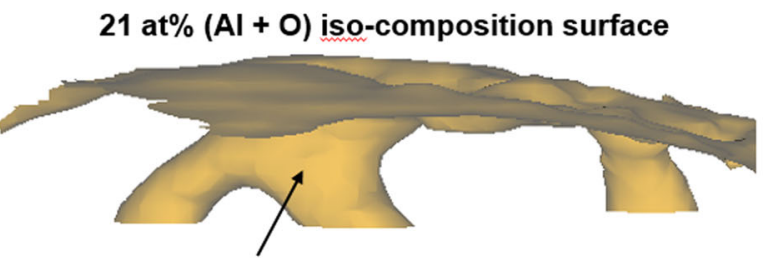

inward-growing oxide

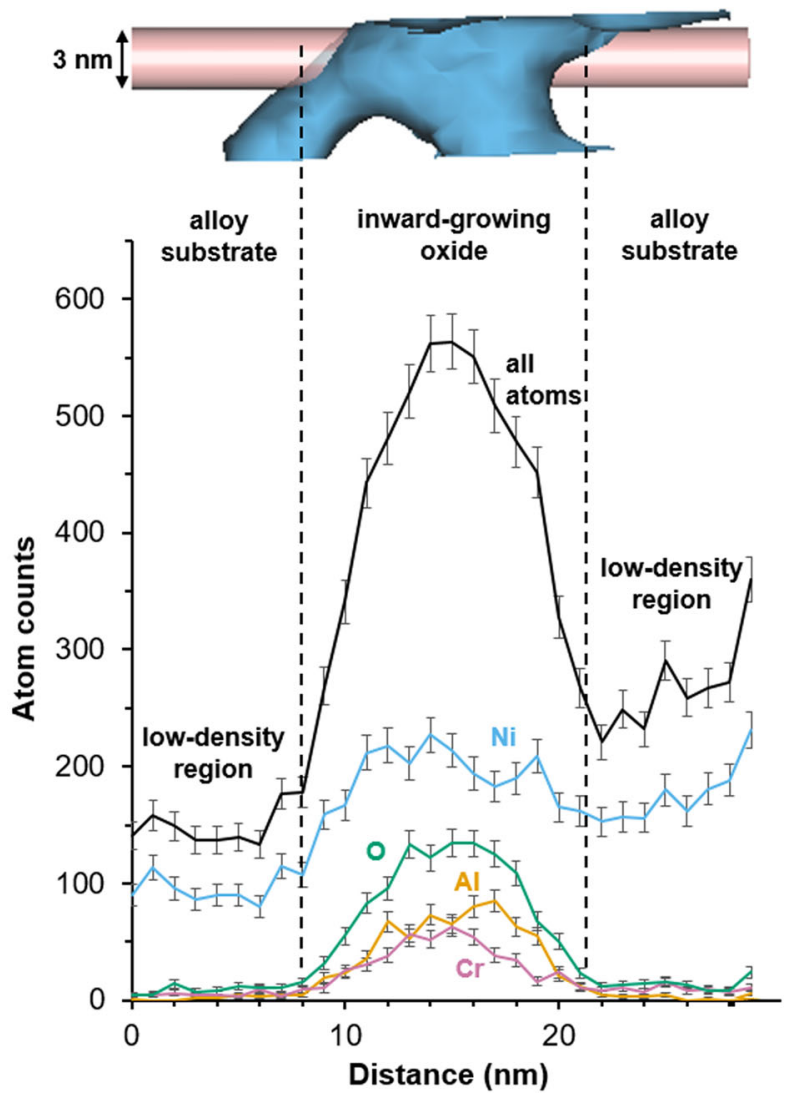

Distance (nm)

Fig. 5 APT compositional analysis of the oxide/alloy interface shown in Fig. 4. a-b Iso-composition surfaces of a region in the alloy immediately below the oxide layer. These surfaces define regions that contain $>55$ at $\% \mathrm{Ni}$ and $>21$ at $\%$ (Al $+\mathrm{O}$ ). c A one-dimensional profile taken through the inward-growing oxide and the adjacent low-density regions. The profile shows the detected total number of atoms and the number of $\mathrm{Ni}, \mathrm{O}, \mathrm{Al}$, and $\mathrm{Cr}$ atoms as a function of distance in the volume defined by the 3-nm diameter cylinder (a 1-nm bin width was used). Error bars represent the square root of the number of detected atoms

oxidized surface of the residual alloy substrate. As expected, the low-density regions, which are located in the $\mathrm{Cr}$-depleted surface of the alloy, are seen to contain considerably less $\mathrm{Cr}$ (at\% $\mathrm{Cr} / \mathrm{Ni} \approx$ 0.06 ) relative to the bulk alloy (at $\% \mathrm{Cr} / \mathrm{Ni} \approx 0.5)$. These APT observations of low-density regions near the inward-growing oxide are consistent with the STEM analysis shown in Fig. 3.

As mentioned above, possible reconstruction artifacts must be considered when interpreting the APT results. Specifically, the lower evaporation field of the oxidized regions could lead to artificial density decreases in adjacent metal regions. Despite this, several features and their consistency with STEM observations point to the existence of real density variations in the material. For example, previous work modeling the effect of evaporation field on spatial overlap found that such overlaps are only expected over relatively short distances $(\approx 3 \mathrm{~nm}$ or less) across varying-field interfaces. $^{30,31}$ For instance, an overlap of $0.1 \mathrm{~nm}$ would be expected for a field difference of $10 \%$, and an overlap of $0.3 \mathrm{~nm}$ for a field difference of $20 \% .{ }^{31}$ In our study, we observed the lowdensity regions over much longer distances $(>10 \mathrm{~nm})$. In addition, as the degree of overlap depends on the difference in evaporation field, one would expect the composition profile (Fig. $5 \mathrm{c}$ ) to reveal local variations based on the different evaporation fields of the elements constituting the alloy. On the contrary, the primary alloying elements $\mathrm{Ni}, \mathrm{Co}$, and $\mathrm{Mo}$ are observed in the low-density regions at ratios close to what is expected for the bulk alloy (Fig. S3). Although the complex nature of the sample does complicate this observation, it is still further evidence that spatial overlaps have not contributed significantly in these regions. In short, although the precise density variation and spatial distribution of such regions cannot be determined, these observations cannot be explained by artifacts alone and do suggest real density decreases in the material.

\section{DISCUSSION}

In considering the STEM and APT results collectively, we now propose the process by which oxide growth has occurred. This process is illustrated schematically in Fig. 6 . The selective oxidation of $\mathrm{Cr}$ results in the outward diffusion of $\mathrm{Cr}$ ions $\left(\mathrm{Cr}^{3+}\right)$ and the creation of metal vacancies $\left(V_{C r}^{0}\right)$ at the oxide/alloy interface. Many of these vacancies are not annihilated, but instead coalesce to form vacancy clusters, leading to low-density regions near the surface of the alloy substrate. During this vacancy coalescence, the modified surface of the alloy substrate becomes oxidized by the oxygen potential established at the oxide/alloy interface. Although this does not necessarily require the inward diffusion of oxygen, the apparent void-filling behavior suggests that some inward diffusion of oxygen has occurred in parallel with the outward diffusion of $\mathrm{Cr}^{3+} .^{32}$ This might occur by diffusion of $\mathrm{O}^{2-}$ as shown in Fig. 6, or by diffusion of molecular oxidant. Such molecular diffusion might occur along grain boundaries, ${ }^{33}$ or through transient nanopores, which form preferentially at the grain boundaries. ${ }^{34,35}$ Because $\mathrm{Al}$ is stable at the lowest oxygen potential among the alloying elements, ${ }^{36}$ it is selectively oxidized in these regions. The oxide formed by this inward growth fills some of the space made available by the departing metal atoms, 
and this results in regions of low-density that contain both $\mathrm{Ni}$ metal and Al-oxide on the near-atomic scale (Figs 3 and 5).

The above processes likely occur in parallel-as vacancies coalesce, Al is oxidized at the free surfaces formed in the alloy, and new Al-oxide in turn provides interfacial sinks for continued coalescence of vacancies. This results in the accumulation of vacancies and thus decrease in density near the oxidized regions, as observed in Fig. 5c. As this process proceeds, a moderate level of vacancy coalescence leads to the intermediate contrast regions observed by STEM imaging (Figs 1 and 3) along most of the oxide/ alloy interface: Al-oxide inside and adjacent to regions of lowdensity metal in the alloy substrate. As vacancies continue to coalesce and $\mathrm{Ni}$ (and other elements not participating in oxidation) diffuse down into the alloy substrate, voids that are large enough to observe in the TEM cross-section are eventually formed adjacent to the Al-oxide. This results ultimately in an Aloxide network inside an otherwise voided region-precisely what is observed in Fig. 2e. Further, we have observed similar voids and porous Al-oxide networks near the oxide/alloy interface for this alloy after much longer exposures $(0.5-500 \mathrm{~h})$, where the oxide thickness ranged from $\approx 0.1-1 \mu \mathrm{m} .{ }^{37}$ After each exposure, the size of these features was always proportional to the thickness of the oxide. This confirms that these features are related to the oxidation process, and provides further evidence that our results have not arisen simply from artifacts inherent to TEM and APT analysis. Finally, this suggests the mechanism proposed here persists for much longer exposure times, and is thus highly relevant to the long-term stability of the alloy.

By the processes described above, voids or other low-density regions can become incorporated into the growing oxide layer. This is illustrated by the inward-growing oxide regions observed by both STEM (Fig. 3) and APT (Fig. 4), which are seen to contain Cr-oxide in addition to Al-oxide. Simultaneous internal and external oxidation of $\mathrm{Cr}$ is not expected for these conditions ${ }^{38}$ and thus these regions cannot be explained simply by an internal oxidation process. These perhaps originated as regions of lowdensity, which were subsequently filled by the inward diffusion of oxygen. Because regions of vacancy accumulation become at least partially filled with oxide, it is difficult to determine by the ex situ analyses shown here precisely what portion of the vacancies have participated. However, the extent of the subsurface features described above suggests that a considerable fraction of the metal vacancies generated during oxidation have indeed contributed to these processes. These results provide direct experimental evidence in support of the Available Space Model, ${ }^{39}$ which has been hypothesized to describe the growth of two-layer oxide

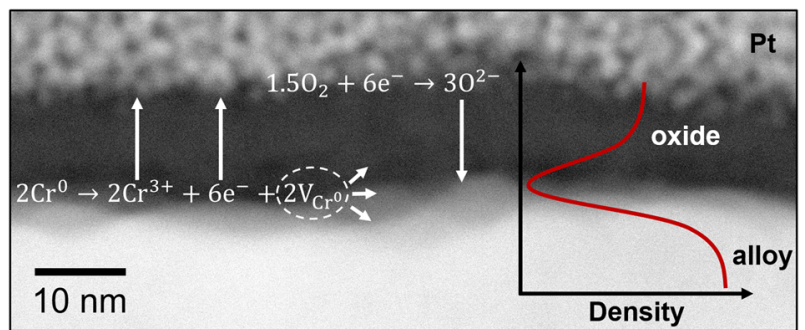

Fig. 6 An annotated version of the STEM image shown in Fig. 1, which summarizes the proposed oxide growth process structures commonly observed on Fe- $\mathrm{Cr}^{40-43}$ and other ${ }^{44}$ alloys. In the proposed model, the outer oxide layer is formed by the outward diffusion of metal cations. The metal vacancies left in the alloy condense to form voids at the oxide/alloy interface, and the inward transport of oxidant fills the voids via oxidation to form the inner oxide layer.

To summarize, we have shown that a considerable fraction of the atomic vacancies generated during high-temperature oxidation can be transferred into the underlying alloy beginning at the very early stages. Contrary to the commonly held belief that such vacancies are primarily annihilated, we show that significant vacancy coalescence can occur that results in a variation in density below the oxide layer ranging from that of the bulk alloy to fully voided regions. These voids and other low-density regions are subsequently oxidized or otherwise incorporated into the growing oxide layer and thus the metal vacancies are shown to have a central role in the oxidation pathway of the alloy.

\section{METHODS}

Alloy preparation and exposure conditions

The detailed experimental conditions were reported previously. ${ }^{22}$ In short, Inconel ${ }^{\circledR}$ alloy 617 (UNS N06617) was obtained in the solutionstrengthened state (average grain size $\approx 90 \mu \mathrm{m}$ ) and exposure samples were cut from the as-received material. The alloy composition provided by the manufacturer is shown in Table 1. The samples were polished to a colloidal silica finish. Optical profilometry measurements of alloys with this finish suggested a surface roughness (Sa) of $11 \pm 2 \mathrm{~nm}$ averaged over large areas $\left(\approx 1 \mathrm{~mm}^{2}\right)$. However, the local roughness determined by STEM imaging of an unexposed sample was considerably smaller, ${ }^{22}$ confirming that the sample features discussed in this paper were not simply an effect of surface finishing. The sample was exposed to $99.999 \% \mathrm{CO}_{2}$ gas at $1 \mathrm{~atm}$ and $700{ }^{\circ} \mathrm{C}$ for $300 \mathrm{~s}$ using an infrared-heated high-temperature furnace. The heating rate was $\approx 5^{\circ} \mathrm{C} / \mathrm{s}$ from room temperature to $700^{\circ} \mathrm{C}$. At the end of exposure, the sample was quenched using $\mathrm{He}$ gas resulting in a cooling rate of $\approx 8^{\circ} \mathrm{C} / \mathrm{s}$ from 700 to $500^{\circ} \mathrm{C}$ and $\approx 4{ }^{\circ} \mathrm{C} / \mathrm{s}$ from 500 to $100^{\circ} \mathrm{C}$. No effect of carbon was observed for exposure to these conditions ${ }^{22}$ and thus the experiment may be regarded as a short duration exposure in a mildly oxidizing environment.

\section{TEM characterization}

Following exposure, samples were prepared for cross-sectional STEM by the focused ion beam method using an FEl Helios NanoLab or FEI Quanta 3D DualBeam scanning electron microscope. STEM images and EDS maps were acquired with an FEl Titan TEM operating at 200 or $300 \mathrm{kV}$ using a HAADF detector and equipped with a chemiSTEM EDS detection system. This imaging mode contains minimal interference effects and is highly sensitive to density variations, where lower density regions appear darker in contrast. ${ }^{45}$ The STEM images were modified using a nonlinear (gamma) correction to highlight regions of intermediate contrast, which were not easily observable in the uncorrected image. EDS maps are presented as raw counts (i.e., not normalized/quantified) to show regions of decreased X-ray intensity corresponding to low-density and/or voided areas. As such, only qualitative comparisons should be made when comparing element distributions from the EDS maps.

\section{APT characterization}

APT is a field-evaporation microscopy technique wherein needle-shaped specimens with $<100 \mathrm{~nm}$ radius are field evaporated. Each atom from the surface is evaporated and reconstructed in three dimensions. The details of the technique can be found in the reference. ${ }^{19}$ APT was used to study the oxide/alloy interface using a Cameca local electrode atom probe (LEAP ${ }^{\circledR}$ ) 4000X HR. The atom probe samples were made in an FEl Helios NanoLab 650 using a lift-out and annular-milling sharpening procedure followed by

Table 1. Composition of Alloy 617 test material

\begin{tabular}{llllllllllllllll}
\hline Element & $\mathrm{Ni}$ & $\mathrm{Cr}$ & $\mathrm{Co}$ & $\mathrm{Mo}$ & $\mathrm{Al}$ & $\mathrm{Fe}$ & $\mathrm{Ti}$ & $\mathrm{C}$ & $\mathrm{Si}$ & $\mathrm{Mn}$ & $\mathrm{Cu}$ & $\mathrm{B}$ & $\mathrm{P}$ & $\mathrm{S}$ \\
\hline at\% & 52.98 & 25.15 & 11.35 & 5.85 & 2.44 & 1.14 & 0.41 & 0.44 & 0.12 & 0.05 & 0.05 & 0.011 & 0.002 & 0.002 \\
\hline
\end{tabular}


a low-energy clean-up to minimize Ga implantation as discussed in the reference. ${ }^{46}$ APT experimental run parameters were optimized by a set of careful experiments. Laser pulsing was done using a UV laser with $\lambda=$ $355 \mathrm{~nm}$, a pulse repetition rate of $125 \mathrm{kHz}$, and a pulse energy of $100 \mathrm{pJ} /$ pulse. An evaporation rate of $0.1 \%$ was used. The sample base temperature was maintained at a setpoint of $40 \mathrm{~K}\left(-233^{\circ} \mathrm{C}\right)$ for all measurements. The atom probe data were analyzed using Image Visualization and Analysis Software (IVASTM) 3.6.12 package. Three specimens were studied and each of them showed similar microstructure features.

Data availability

All relevant data that support this study are available from the corresponding author upon request.

\section{ACKNOWLEDGEMENTS}

This work was performed in support of the U.S. Department of Energy's Fossil Energy Crosscutting Technology Research and Advanced Turbine Programs. The Research was executed through NETL Research and Innovation Center's Advanced Alloy Development Field Work Proposal. Research performed by AECOM Staff was conducted under the RES contract DE-FE0004000. This research was supported in part by appointments (RPO and MK) to the NETL Research Participation Program sponsored by the U.S. Department of Energy and administered by the Oak Ridge Institute for Science and Education. A portion of the research was performed using EMSL, a DOE Office of Science User Facility sponsored by the Office of Biological and Environmental Research. We thank Dr. Jinichiro Nakano and Dr. Anna Nakano for use of the high-temperature confocal scanning laser microscope in the CorrosionElectrochemistry Laboratory at NETL. We further thank Joshua Razink (Center for Advanced Materials Characterization in Oregon; Eugene, OR USA) for assistance with some of the STEM imaging. This project was funded by the Department of Energy, National Energy Technology Laboratory, an agency of the United States Government, through a support contract with AECOM. Neither the United States Government nor any agency thereof, nor any of their employees, nor AECOM, nor any of their employees, makes any warranty, expressed or implied, or assumes any legal liability or responsibility for the accuracy, completeness, or usefulness of any information, apparatus, product, or process disclosed, or represents that its use would not infringe privately owned rights. Reference herein to any specific commercial product, process, or service by trade name, trademark, manufacturer, or otherwise, does not necessarily constitute or imply its endorsement, recommendation, or favoring by the United States Government or any agency thereof. The views and opinions of authors expressed herein do not necessarily state or reflect those of the United States Government or any agency thereof.

\section{AUTHOR CONTRIBUTIONS}

R.P.O. performed the TEM analysis, conceived of and wrote the manuscript. M.K. and D.E.P. performed the APT analysis. G.R.H. and O.N.D. provided guidance throughout the project. All authors participated in discussion of the results and editing of the manuscript.

\section{ADDITIONAL INFORMATION}

Supplementary Information accompanies the paper on the npj Materials Degradation website (https://doi.org/10.1038/s41529-018-0046-1).

Competing interests: The authors declare no competing interests.

Publisher's note: Springer Nature remains neutral with regard to jurisdictional claims in published maps and institutional affiliations.

\section{REFERENCES}

1. Young, D. J. High temperature oxidation and corrosion of metals. Vol. 2 (Elsevier, 2016).

2. Wagner, C. Theory of the tarnishing process. Z. Phys. Chem. 21, 25-41 (1933)

3. Gibbs, G. B. \& Hales, R. The influence of metal lattice vacancies on the oxidation of high temperature materials. Corros. Sci. 17, 487-507 (1977).

4. Harris, J. E. Vacancy injection during oxidation-a re-examination of the evidence. Acta Metall. 26, 1033-1041 (1978).

5. Francis, R. \& Lees, D. Evidence for vacancy injection during the oxidation of iron. Mater. Sci. Eng. A 120, 97-99 (1989).
6. Perusin, S., Viguier, B., Monceau, D., Ressier, L. \& Andrieu, E. Injection of vacancies at metal grain boundaries during the oxidation of nickel. Acta Mater. 52, 5375-5380 (2004).

7. Maurice, V., Despert, G., Zanna, S., Bacos, M.-P. \& Marcus, P. Self-assembling of atomic vacancies at an oxide/intermetallic alloy interface. Nat. Mater. 3, 687-691 (2004).

8. Hales, R., Dobson, P. \& Smallman, R. The production of vacancies by oxidation in zinc and magnesium. Met. Sci. 2, 224-227 (1968).

9. Hou, P. Y., Niu, Y. \& Van Lienden, C. Analysis of pore formation at oxide-alloy interfaces-l: Experimental results on FeAl. Oxid. Met. 59, 41-61 (2003).

10. Islam, M. M., Diawara, B., Maurice, V. \& Marcus, P. Atomistic modeling of voiding mechanisms at oxide/alloy interfaces. J. Phys. Chem. C. 113, 9978-9981 (2009).

11. Shida, Y., Wood, G. C., Stott, F. H., Whittle, D. P. \& Bastow, B. D. Intergranular oxidation and internal void formation in Ni-40\% Cr alloys. Corros. Sci. 21, 581-597 (1981).

12. Kirkendall, E. Diffusion of zinc in alpha brass. Trans. A.I.M.E 147, 104-109 (1942).

13. Cao, G. Atomic level understanding of the nanoscale Kirkendall effect. Sci. Bull. 62, 818-819 (2017)

14. Yin, Y. et al. Formation of hollow nanocrystals through the nanoscale Kirkendall effect. Science 304, 711-714 (2004).

15. Wang, W., Dahl, M. \& Yin, Y. Hollow nanocrystals through the nanoscale Kirkendall effect. Chem. Mater. 25, 1179-1189 (2013)

16. Wang, C.-M., Schreiber, D. K., Olszta, M. J., Baer, D. R. \& Bruemmer, S. M. Direct in situ TEM observation of modification of oxidation by the injected vacancies for $\mathrm{Ni}-4 \mathrm{Al}$ alloy using a microfabricated nanopost. ACS Appl. Mater. Inter. 7 17272-17277 (2015).

17. Hou, P. Y, Van Leiden, C, Niu, Y. \& Gesmundo, F. Quantitative assessment of pore development at A/2O3/FeAl interfaces during high temperature oxidation. Report No. LBNL-47685, 1-13, ((Lawrence Berkeley NationalLaboratory: Berkeley, CA 2001.

18. Xu, N., Monceau, D., Young, D. \& Furtado, J. High temperature corrosion of cast heat resisting steels in $\mathrm{CO}+\mathrm{CO}_{2}$ gas mixtures. Corros. Sci. 50, 2398-2406 (2008).

19. Miller, M. K. \& Forbes, R. G. Atom-probe tomography: the local electrode atom probe. (Springer, 2014).

20. INCONEL ${ }^{\circledR}$ alloy 617. Report No. SMC-029, 1-12 (Special Metals Corporation, 2005).

21. Giggins, C. S. \& Pettit, F. S. Oxidation of Ni-Cr-Al alloys between $1000^{\circ}$ and $1200^{\circ}$ C. J. Electrochem. Soc. 118, 1782-1790 (1971).

22. Oleksak, R. P. et al. Mechanistic insights into the oxidation behavior of Ni alloys in high-temperature $\mathrm{CO}_{2}$. Corros. Sci. 125, 77-86 (2017).

23. Evans, H. E. Cavity formation and metallurgical changes induced by growth of oxide scale. Mater. Sci. Technol. 4, 1089-1098 (1988).

24. Desgranges, C., Lequien, F., Aublant, E., Nastar, M. \& Monceau, D. Depletion and voids formation in the substrate during high temperature oxidation of $\mathrm{Ni}-\mathrm{Cr}$ alloys. Oxid. Met. 79, 93-105 (2013)

25. Larson, D. J., Gault, B., Geiser, B. P., De Geuser, F. \& Vurpillot, F. Atom probe tomography spatial reconstruction: status and directions. Curr. Opin. Solid State Mater. Sci. 17, 236-247 (2013)

26. Miller, M. K., Longstreth-Spoor, L. \& Kelton, K. Detecting density variations and nanovoids. Ultramicroscopy 111, 469-472 (2011).

27. Edmondson, P. D., Parish, C. M., Zhang, Y., Hallén, A. \& Miller, M. K. Helium entrapment in a nanostructured ferritic alloy. Scr. Mater. 65, 731-734 (2011).

28. Edmondson, P., Parish, C., Zhang, Y., Hallén, A. \& Miller, M. Helium bubble distributions in a nanostructured ferritic alloy. J. Nucl. Mater. 434, 210-216 (2013).

29. Devaraj, A. et al. Discerning the location and nature of coke deposition from surface to bulk of spent zeolite catalysts. Sci. Rep. 6, 37586 (2016).

30. Vurpillot, F., Bostel, A. \& Blavette, D. Trajectory overlaps and local magnification in three-dimensional atom probe. Appl. Phys. Lett. 76, 3127-3129 (2000).

31. Blavette, D., Vurpillot, F., Pareige, P. \& Menand, A. A model accounting for spatial overlaps in 3D atom-probe microscopy. Ultramicroscopy 89, 145-153 (2001).

32. Henry, S., Mougin, J., Wouters, Y., Petit, J.-P. \& Galerie, A. Characterization of chromia scales grown on pure chromium in different oxidizing atmospheres. Mater. High Temp. 17, 231-234 (2000)

33. Young, D. J., Nguyen, T. D., Felfer, P., Zhang, J. \& Cairney, J. M. Penetration of protective chromia scales by carbon. Scr. Mater. 77, 29-32 (2014).

34. Atkinson, A. Transport processes during the growth of oxide films at elevated temperature. Rev. Mod. Phys. 57, 437 (1985).

35. Harris, A. \& Atkinson, A. Oxygen transport in growing nickel oxide scales at 600-800 ${ }^{\circ}$ C. Oxid. Met. 34, 229-258 (1990).

36. Ellingham, H. J. T. Reducibility of oxides and sulfides in metallurgical processes. J. Soc. Chem. Ind. 63, 125-133 (1944).

37. Oleksak, R. P., Carney, C. S., Holcomb, G. R. \& Doğan, Ö. N. Structural evolution of a $\mathrm{Ni}$ alloy surface during high-temperature oxidation. Oxid. Met. 90, pp 27-42 (2017). 
38. Holcomb, G. R. et al. Hydrogen transport during steam oxidation of iron and nickel alloys. Mater. High Temp. (submitted).

39. Robertson, J. \& Manning, M. I. Criteria for formation of single layer, duplex, and breakaway scales on steels. Mater. Sci. Technol. 4, 1064-1071 (1988).

40. Brückman, A., Emmerich, R. \& Mrowec, S. Investigation of the high-temperature oxidation of $\mathrm{Fe}-\mathrm{Cr}$ alloys by means of the isotope ${ }^{18} \mathrm{O}$. Oxid. Met. 5, 137-147 (1972).

41. Cox, M., McEnaney, B. \& Scott, V. Vacancy condensation and void formation in duplex oxide scales on alloys. Philos. Mag. 28, 309-319 (1973).

42. Martinelli, L. et al. Oxidation mechanism of an $\mathrm{Fe}-9 \mathrm{Cr}-1 \mathrm{Mo}$ steel by liquid $\mathrm{Pb}-\mathrm{Bi}$ eutectic alloy at $470^{\circ} \mathrm{C}$ (Part II). Corros. Sci. 50, 2537-2548 (2008).

43. Rouillard, F. \& Furukawa, T. Corrosion of 9-12Cr ferritic-martensitic steels in hightemperature $\mathrm{CO}_{2}$. Corros. Sci. 105, 120-132 (2016).

44. Atkinson, A. \& Smart, D. Transport of nickel and oxygen during the oxidation of nickel and dilute nickel/chromium alloy. J. Electrochem. Soc. 135, 2886-2893 (1988).

45. Nellist, P. D. \& Pennycook, S. J. The principles and interpretation of annular darkfield Z-contrast imaging. Adv. Imag. Elect. Phys. 113, 147-203 (2000).
46. Thompson, K. et al. In situ site-specific specimen preparation for atom probe tomography. Ultramicroscopy 107, 131-139 (2007).

cC (i) Open Access This article is licensed under a Creative Commons Attribution 4.0 International License, which permits use, sharing, adaptation, distribution and reproduction in any medium or format, as long as you give appropriate credit to the original author(s) and the source, provide a link to the Creative Commons license, and indicate if changes were made. The images or other third party material in this article are included in the article's Creative Commons license, unless indicated otherwise in a credit line to the material. If material is not included in the article's Creative Commons license and your intended use is not permitted by statutory regulation or exceeds the permitted use, you will need to obtain permission directly from the copyright holder. To view a copy of this license, visit http://creativecommons. org/licenses/by/4.0/.

(c) The Author(s) 2018 